\title{
EVALUATION OF PLASMA CELL PROPIDIUM-IODIDE AND ANNEXIN-V INDICES: THEIR RELATION TO PROGNOSIS IN MULTIPLE MYELOMA
}

\author{
Jiří Minařík $k^{\mathrm{a}}$, Vlastimil Ščudlaa , Marta Ordeltováb, Jaroslav Bačovskýa, Markéta Zemanováa \\ a $3^{\text {rd }}$ Department of Internal Medicine, Teaching Hospital Olomouc, Palacký University Olomouc, Czech republic \\ ${ }^{b}$ Department of Clinical Immunology, Teaching Hospital Olomouc, Palacky University Olomouc
}

Received: September 29, 2005; Accepted (with revisions): November 15, 2005

Key words: Multiple myeloma/Propidium-iodide index/Annexin-V index/Apoptosis/Plasma cells/Overall survival

In a group of 117 patients with multiple myeloma (MM) examined at the time of diagnosis, i.e. excluding previous chemotherapy, we analysed the levels of propidium-iodide (proliferative) - PC-PI/CD ${ }_{138}$ and annexin-V (apoptotic) - PC-AI/CD ${ }_{138}$ indices of myeloma plasmocytes using the method of flow-cytometry to determine their relationship to prognosis. It was revealed that patients with high values of PC-PI/CD ${ }_{138}$ had substantially worse overall survival than those with low values. Patients with a level of propidium-iodide index $\geq 2,8 \%$ exprimed a median survival of 13 months only in comparison with 42 months in patients with levels $<2,8 \%(\mathrm{p}=0,0005)$. In the PC-AI/CD $\mathrm{CD}_{138}$ index a reverse trend was registered. Patients with PC-AI/CD $\mathrm{CD}_{138} \geq 4,0 \%$ had long overall survival (median was not assessable at the time of evaluation), whereas patients with low apoptosis values $<4,0 \%$ had median overall survival 16 months only ( $p=0,01)$. Based on the sequentional graphic analysis of the curves of overall survival was found that the optimal discrimination level sequestering patients with good and poor prognosis was, in the case of PC-PI/CD ${ }_{138}$ value $2,8 \%$, whereas in the case of PC-AI/CD ${ }_{138}$ value $4,0 \%$. Among patients with good prognosis, there were no statistically significant differences in overall survival according to different levels of proliferative and apoptotic index. We conclude that evaluation of the propidium-iodide and annexin- $\mathrm{V}$ index using flow-cytometry is a quick, useful, and easily accessible method for the evaluation of plasma cell kinetics and thus prognosis of the disease, multiple myeloma.

\section{INTRODUCTION}

Multiple myeloma is a malignant clonal disease caused by proliferation and accumulation of neoplastically transformed terminally differentiated B-lymphocytes ${ }^{1}$. Its incidence in population is about 5.3/100 000 in men and $3.5 / 100000$ in women and it constitues up to $8 \%$ of all haematological malignancies ${ }^{2}$. Standard diagnostic criteria rely on the appearance of a range of symptoms, that are often manifested in the course of the disease - CRABI (hypercalcaemia, renal failure, anaemia, bone lesions and immunodeficiency), and were proclaimed first within Southwest Oncology Group (SWOG) ${ }^{3}$, later on within the International Myeloma Working Group (IMWG) These symptoms represent the actual load of the tumour and the degree of damage to individual organs. However, they do not tell us much about the prognosis of the disease. Multiple myeloma accrues from a link of two processes - proliferation and accumulation, that ultimately reveal the potential of the disease to grow/cease and are the key mechanism to determine a future behaviour of the disease. With this knowledge we studied two cytokinetic indices, i.e. proliferation and apoptosis. The expansion of myeloma cell neoplastic clone is determined by the equilibrium between proliferation, on the one hand, and induction or blockade of apoptosis on the other hand ${ }^{5}$. In the past few years, methods of detecting proliferation based on evaluation of propidium-iodide index have been established ${ }^{6-12}$, but the study of apoptosis remains in large part unexplored and limited to a few clinically oriented studies $^{1,13,14}$, most published studies are in vitro based.

The aim of this study was to measure the cytokinetic indices (propidium iodide and annexin- $\mathrm{V}$ index) at the time of diagnosis - which means unaffected by previous treatment - and to establish a clear relationship of their values to prognosis, determined by overall survival (OS). Moreover, we have tried to determine the optimum discrimination levels of these indices that would distribute patients into prognostically different groups.

\section{PATIENTS AND METHODS}

The group analysed consisted of 117 patients with multiple myeloma examined from 2000-2004, at the time of MM diagnosis. The criteria for eligibility for the study were standard SWOG criteria ${ }^{3}$. For clinical staging we used the Salmon-Durie stratification system. According to this staging there were 15 (13\%) of stage I patients, 50 (43\%) stage II and 52 (44\%) stage III patients (Table 1). Patients with „smoldering“ untreated multiple myeloma were excluded from the study. The patients were treated using „conventional chemotherapy“ (i.e. regimen VBMCP, VAD, MP, CyVAD and CIDex). Patients treated using regimen with HD-chemotherapy supported by autologous peripheral stem cell transplantation and those treated 
Table 1. Characteristics of the analysed group of 117 patients with multiple myeloma at the time of diagnosis of the disease, devided according to clinical staging system of Durie-Salmon and according to distribution of immunochemical types of monoclonal immunoglobulin

\begin{tabular}{|c|c|c|c|c|c|c|c|c|c|c|c|c|c|c|}
\hline & & \multicolumn{5}{|c|}{ Stage (D-S) } & \multicolumn{5}{|c|}{ Immunochemical type } \\
\hline $\mathrm{n}$ & $\mathrm{M} / \mathrm{F}$ & $\begin{array}{c}\text { Age } \\
\text { median } \\
(\text { years })\end{array}$ & $\begin{array}{c}\mathrm{I}(\%) \\
\mathrm{n}(\%)\end{array}$ & $\begin{array}{c}\mathrm{II} \\
\mathrm{n}(\%)\end{array}$ & $\begin{array}{c}\mathrm{III} \\
\mathrm{n}(\%)\end{array}$ & $\begin{array}{c}\mathrm{A} \\
\mathrm{n}(\%)\end{array}$ & $\begin{array}{c}\mathrm{B} \\
\mathrm{n}(\%)\end{array}$ & $\begin{array}{c}\text { IgG } \\
\mathrm{n}(\%)\end{array}$ & $\begin{array}{c}\text { IgA } \\
\mathrm{n}(\%)\end{array}$ & $\begin{array}{c}\text { IgM } \\
\mathrm{n}(\%)\end{array}$ & $\begin{array}{c}\text { B-J } \\
\mathrm{n}(\%)\end{array}$ & $\begin{array}{c}\text { NS } \\
\mathrm{n}(\%)\end{array}$ & $\begin{array}{c}\text { Kappa } \\
\mathrm{n}(\%)\end{array}$ & $\begin{array}{c}\text { Lambda } \\
\mathrm{n}(\%)\end{array}$ \\
\hline 117 & 0,92 & $\begin{array}{c}66 \\
(44-85)\end{array}$ & $\begin{array}{c}15 \\
(13)\end{array}$ & $\begin{array}{c}50 \\
(43)\end{array}$ & $\begin{array}{c}52 \\
(44)\end{array}$ & $\begin{array}{c}87 \\
(74)\end{array}$ & $\begin{array}{c}30 \\
(26)\end{array}$ & $\begin{array}{c}81 \\
(69)\end{array}$ & $\begin{array}{c}23 \\
(20)\end{array}$ & $\begin{array}{c}1 \\
(1)\end{array}$ & $\begin{array}{c}11 \\
(9)\end{array}$ & $\begin{array}{c}1 \\
(1)\end{array}$ & $\begin{array}{c}77 \\
(66)\end{array}$ & $\begin{array}{c}39 \\
(33)\end{array}$ \\
\hline
\end{tabular}

$\mathrm{n}$ - number of patients, M - male, F - female, D-S - staging system according Durie-Salmon, NS - nonsecretory type

eventually with novel drugs (thalidomide, bortezomib) were not included in this study ${ }^{15-18}$.

Analysed mean proliferative activity of the plasma cell population using propidium-iodide index was measured with the method of flow cytometry (DNA - Prep Reagents Kit, Coulter, software Multicycle fy. Phoenix) to represent the proportion of S-phase plasma cells ${ }^{12}$. Using a DNA/CD ${ }_{138}$ double staining technique allowed us to assess the rate of propidium iodide incorporation into nuclear DNA, while plasma cells were identified by MoAb against syndecan-1 $\left(\mathrm{CD}_{138}\right)^{1,19}$. Propidium-iodide index was examined in a bone marrow aspirate after separation of cells using a density gradient (Ficoll Verografin). The median PC-PI/CD $\mathrm{CD}_{138}$ was determined by a multiparametric analysis of 2000-4000 cells $\mathrm{s}^{10,12}$. The means of apoptosis determined by annexin-V index was measured again using flow cytometry, to represent the proportion of plasma cells undergoing apoptosis. After separation of bone marrow aspirate using a density gradient and identification of myeloma plasma cells with MoAb anti- $\mathrm{CD}_{138}\left(\mathrm{CD}_{138}\right.$ $\mathrm{PE}$, Biotech) the cells were incubated, washed with phosphate-buffered saline (PBS), and resuspended in binding solution. Annexin-V FITC kit (Immunotech, Marseille, France) was used to detect phosphatidyl-serine expression on the surface of apoptotic cells. For statistical estimation $\log$ rank test and Kaplan-Meier analysis were used.

\section{RESULTS}

Propidium iodide index, measured at the time of diagnosis varied in range from $0,4-4,8 \%$ (median 2,6\%). Dividing the 117 patients into 2 separate groups according to the median of their proliferative index, we established the patients with poor and good prognosis (Fig. 1). Propidium iodide index of $\geq 2.6 \%$ meant lower overall survival (OS) of 18 months only, while the values below $2.6 \%$ showed the OS of 32 months $(p=0,05)$. Using a mathematical analysis we tried to find the optimal discrimination level, that would best demark the groups of poor and good prognosis. The most statistically significant value of propidium-iodide was $2.8 \%$ (Fig. 2). In this case we could divide patients with median OS of 13 months for the level of proliferation $\geq 2.8 \%$ and the group of patients with median OS of 42 months for the level of proliferation below $2.8 \%(\mathrm{p}=0,0005)$. Continuing the analysis we depicted lower levels of PC-PI (2.6, 2.5, 2.4, $2.2,2.0 \%$ ) to find a value of "best prognosis". The results of this analysis, however, were not statistically significant. Similar analysis was carried out for the values of annexin$\mathrm{V}$ index. The range was $1.4-24.5 \%$ (median $5.1 \%$ ). The establishement of Kaplan-Meier curve of overall survival according to the level of apoptosis behaved in a reverse manner. The group of patients with apoptosis $\geq 5,1 \%$ had longer OS (not reaching the median yet), while those with low apoptotic rate had an OS of 20 months $(p=0,04)$ (Figure 3). The mathematical analysis of discrimination values identified the optimum at the level of PC-AI $4.0 \%$. Patients with lower apoptotic rate had median OS 16 months only, while in the group with apoptosis of $\geq 4.0 \%$ median was not reached at the time of statistical analysis $(p=0,01)$, (Fig. 4). Similarly as in the case of propidiumiodide index, there was not a statistical significance for higher discrimination levels $(4.5,5.0,5.5,6.0,7.0,8.0 \%)$, that would distinguish patients with a "very good" prognosis.

\section{DISCUSSION}

The neoplastic population of plasma cells forms a 3 compartment pool: (1) compartment of stem cells - only a small percentage (1-2\%) of totipotent cells that merge into the next compartment - (2) compartment of proliferating plasma cells (about $1-4 \%$ ), again a very small compartment, but plays an important role in growth and expansion of plasma cells by supplying the vast tumour mass, and finally (3) differentiation compartment (over $90 \%$ ) that contains the real tumour mass, cells do stop their proliferation, undergo maturation and eventually may become senescent and apoptotic ${ }^{16,20}$.

Recent studies have proved, that among the most important prognostic factors for multiple myeloma are those that reflect the specific characteristics of the malignant clone $\mathrm{e}^{21}$. Stress was put especially on proliferation, as the marker of tumour cell aggresiveness and growth 


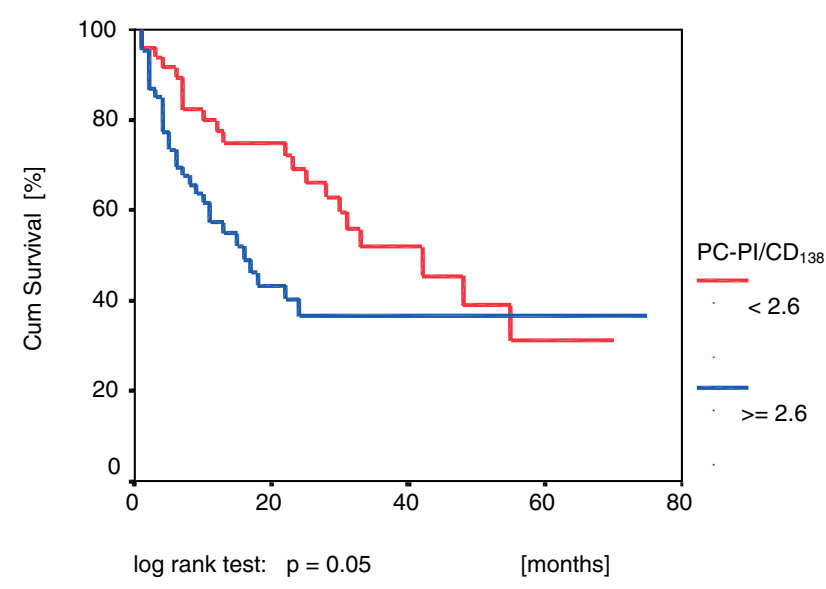

Fig. 1. Plasma cell propidium-iodide index and KaplanMeier curve of length of survival in all patients. Group devided according to median.

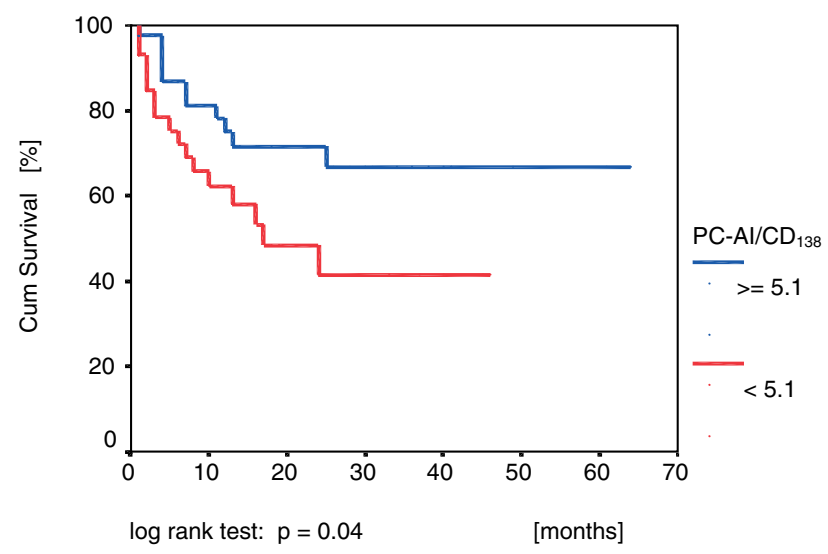

Fig. 3. Plasma cell annexin-V (apoptotic) index in all patients - group devided according to median.

potency ${ }^{1,8,9,12}$, some of the authors even including the proliferation characteristics as an important part of new staging systems in multiple myeloma ${ }^{10}$. Our study aims directly to the relation of plasma cell proliferation (represented by propidium-iodide index) to the prognosis of the disease thus to establish the PC-PI an important and independent prognostic factor ${ }^{5,22,23}$. High percentage of S-phase plasmocytes (i.e. PC-PI/CD ${ }_{138}$ ) means poor prognosis, whereas the low levels represent a good prognosis. The prognosis, however, does not change in an inverse proportionality to the values of propidium-iodide index. In our group we identified the optimal discrimination value of PC-PI at $2.8 \%$, compared to $3.0 \%$ in original study of San Miguel. Patients with lower proliferation have relatively good prognosis with no significant differences among this group (individual lower values did not mean significantly better prognosis). Those with values above $2.8 \%$ had all substantially lower OS.

Assessment of proliferation alone, however, is not sufficient to evaluate myeloma growth ${ }^{24}$. The expansion or decrease of myeloma tumour mass depends on the bal-

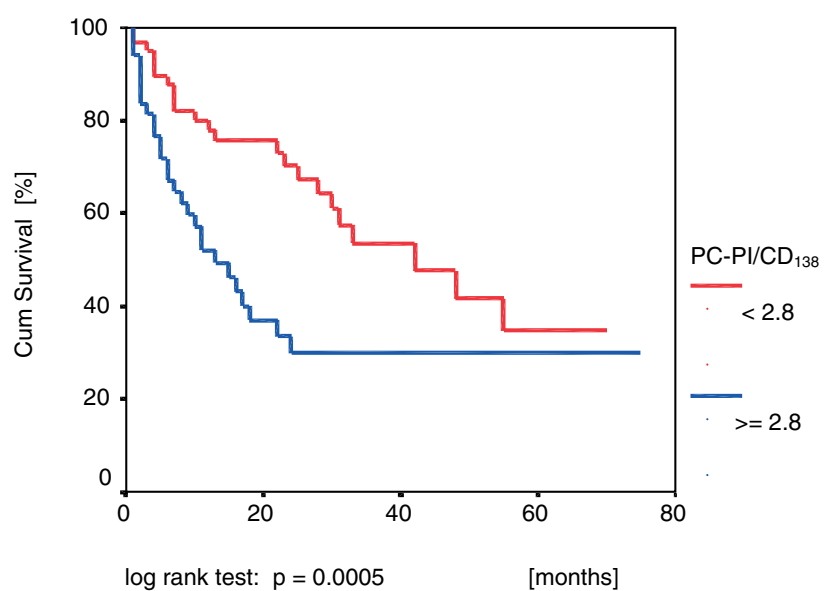

Fig. 2. Kaplan-Meier curve of overall survival in patients with multiple myeloma - optimal discrimination level of PC-PI/CD ${ }_{138}$ at $2.8 \%$.

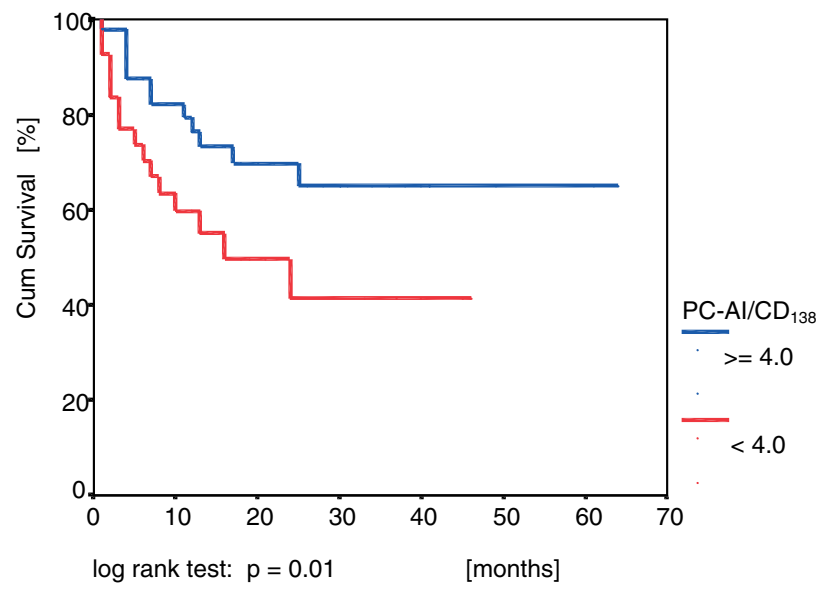

Fig. 4. Annexin-V index - Kaplan-Meier curve of OS - optimal discrimination level of PC-AI/CD $\mathrm{CD}_{138}$ at $4,0 \%$.

ance of proliferation and apoptosis. Plasma cells owe their long-life survival to defective apoptosis ${ }^{25}$. Ability to avoid apoptosis extends the life of plasma cells, supports the growth of tumour and takes part in the drug resistance of multiple myeloma. Prior infrequent studies dealing with apoptosis suggested a conception of inverse relation to proliferation of plasma cells ${ }^{1,13}$. The balance on behalf of tumour growth or shrinkink may be however disrupted by levels of apoptosis only - even a vigorous proliferation may be compensated by normal (high) apoptotic rate, on the other hand, a slowly proliferating tumour may cause serious damage in case of apoptotic disruption. In our study, similarly as Witzig ${ }^{13}$, we confirmed the tight relation between apoptotic rate and prognosis of multiple myeloma - higher levels of apoptosis meant good prognosis, whereas lower values stratified the patients into a poorprognostic group. The optimal cut off value isolating good and poor prognostic groups was at $4.0 \%$, although the statistical significance was not as strong as in the case of PC-PI - probably due to the wider range of the values and 
probably due to a number of extrinsic and intrinsic influences, affecting the process of apoptosis of plasma cells.

The stratification of patients into groups of good and poor prognosis according to PC-PI and PC-AI takes a broad view of the disease, providing valuable information about the behaviour of different populations of plasma cells. Our study, however, implies not only prognostic, but also therapeutic conclusions. With the knowledge of approximate prognosis of individual patients we are able to establish a clear change of pattern and intensity in our therapeutical aims. Patients with good prognosis may be treated with less aggressive chemotherapy, thus to expose them to less toxic consequences of the treatment, those with poor prognosis should be carefully monitored as for the treatment response, the treatment should be more intense and perhaps for a long lasting period.

\section{ACKNOWLEDGEMENT}

This study was supported by grant IGA CR MHCR NC 7503-3 and MSM 6198959205.

\section{REFFERENCES}

1. Scudla, V., Ordeltova, M., Bacovsky, J., Vytrasova, M., Sumna, E., Martinek, A., Horak, P. (2003) A contribution to examination of propidium iodide and annexin $\mathrm{V}$ plasma cells indices in multiple myeloma. Neoplasma, 50, 363-371.

2. Desikan, R., Jagannath, S., Richardson, P., Munshi, N. C. Multiple myeloma and other plasma cell dyscrasias. In: Pazdur, R., Coia, L. R., Hoskins, W. J., Wagman, L.D., editors. Cancer Management: A Multidisciplinary Approach, Eight edition. CMP Healthcare Media, 2004. p. 727-745.

3. Southwest Oncolology Group. Remission maintenance therapy for multiple myeloma. (1975) Arch. Int. Med., 135, 147-152.

4. The International Myeloma Working Group (2003) Criteria for the classification of monoclonal gammopathies, multiple myeloma and related disorders: a report of the International Myeloma Worging Group. Brit. J. Haematol., 121, 749-757.

5. Greipp, P. R., Lust, J. A., O’Fallon, W. M., Katzmann, J. A., Witzig, T. E., Kyle, R. A. (1993) Plasma cell labeling index and beta 2-microglobulin predict survival independent of thymidine kinase and C-reactive protein in multiple myeloma. Blood, 81, 3382-3387.

6. Greipp, P. R., Katzmann, J. A., O’Fallon, W. M., Kyle, R. A. (1988) Value of Beta-2-Microglobulin Level and Plasma Cell Labeling Indices as Prognostic Factors in Patients With Newly Diagnosed Myeloma. Blood, 72, 219-223.

7. Rajkumar, S. V., Fonseca, R., Dewald, G. W., Therneau, T. M., Lacy, M. Q., Kyle, R. A., Greipp P. R., Gertz, M. A. (1999) Cytogenetic Abnormalities Correlate with the Plasma Cell Labeling Index and Extent of Bone Marrow Involvement in Myeloma. Cancer Genet. Cytogenet., 113, 73-77.

8. Boccadoro, M., Marmont, F., Tribalto, M., Fossati, G., Redoglia, V., Battaglio, S., Massai, M., Gallamini, A., Comotti, B., Barbui, T. (1989) Early responder myeloma: kinetic studies identify a patient soubgroup characterized by very poor prognosis. J. Clin. Oncol., 7, 119-125.

9. Joshua, D., Petersen, A., Brown, R., Pope, B., Snowdon, L., Gibson, J. (1996) The labeling index of primitive plasma cells determines the clinical behaviour of patients with myelomatosis. Brit. J. Haematol., 64, 76-81.
10. San Miguel, J. F., García-Sanz, R., Gonzáles, M., Moro, M. J., Hernández, J. M., Ortega, F., Borrego, D., Carnero, M., Casanova, F., Jinémez, R., Portero, J. A., Orfao, A. (1995) A new staging system for multiple myeloma based on the number of S-phase plasma cells. Blood, 85, 448-455.

11. Scudla, V., Bacovsky, J., Vytrasova, M., Zurek, M., Ordeltova, M. (2002) Contribution to examination of propidium iodide and annexin-V indices of plasma cells in multiple myeloma. Int. J. Hematol., 76, Suppl I: 24.

12. Scudla, V., Ordeltova, M., Spidlova, A., Bacovsky, J., Kurasova, J., Vranova, V. (1999) Importance of examination of the propidiumiodide index of plasmocytes in multiple myeloma. I. relation to some laboratory findings of the disease. II. Relationship with extent and activity of the disease. Vnitr. Lek., 45, 331-335, 336-341.

13. Witzig, T. E., Timm, M., Larson, D., Therneau, T., Greipp, P. R. (1999) Measurement of apoptosis and proliferation of bone marrow plasma cells in patients with plasma cell proliferative disorders. Brit. J. Haematol., 104, 131-137.

14. Xu, J. L. Lai, R., Kinoshita, T., Nakashima, N., Nagasaka, T. (2002) Proliferation, apoptosis, and intratumoral vascularity in multiple myeloma: correlation with the clinical stage and cytological grade. J. Clin. Pathol., 55, 530-534.

15. Boccadoro, M., Tarella, C., Palumbo, A., Argentino, Ch., Triolo, S., Dominietto, A., Callea, V., Lauta, V. M., Mouca, S., Musto, P., Marmont, F., Gianni, A. M., Pileri, A. (1999) An analysis of which subgroups of multiple myeloma patients, divided according to Beta-2-microglobulin and plasma cell labeling index, benefit from high dose vs conventional chemotherapy. Haematologica, 84 , 905-910.

16. Anderson, K. C. (2001) Targeted therapy for multiple myeloma. Semin. Hematol., 38, 286-94.

17. Barclay, L., Lie, D. (2005) Bortezomib May Be Superior to HighDose Dexamethasone in Multiple Myeloma. N. Engl. J. Med., 352, 2487-2498.

18. Davies, F. E., Anderson, K. C. (2000) Novel therapeutic targets in multiple myeloma. Eur. J. Hematol., 64, 359-367.

19. Orfáo, A., García-Sanz, R., Lopéz-Berges, M. C., Vidriales, M. B., Gonzáles, M., Caballero, M. D., San Miguel, J. F. (1994) A New method for the Analysis of Plasma Cell DNA Content in Multiple Myeloma Samples Using a CD38/Propidium Iodide Double Staining Technique. Cytometry, 17, 1-8.

20. Vacca, A., Ribatti, D., Roncali, L., Dammacco, F. (1995) Angiogenesis in B Cell Lymphoproliferative Diseases. Biological and Clinical Studies. Leukemia and Lymphoma, 20, 27-38.

21. San Miguel, J. F., García-Sanz, R. Multiple myeloma: differential diagnosis and prognosis. In: Wiernik, P. H., Goldman, J. M., Dutcher, J. P., Kyle, R. A. Neoplastic Diseases of the Blood, Fourth Edition. Cambridge University Press, 2003. p. 179-199.

22. Joshua, D., Petersen, A., Brown, R., Pope, B., Snowdon, L., Gibson J. (1996) The labeling index of primitive plasma cells determines the clinical behaviour of patients with myelomatosis. Brit. J. Haematol., 94, 76-81.

23. Ffrench, M., Ffrench, P., Remy, F., Chapuis-Cellier, C., Wolowiec, D., Ville, D., Bryon, P. A. (1995) Plasma Cell Proliferation in Monoclonal Gammopathy: Relations With Other Biologic Variables - Diagnostic and Prognostic Significance. Amer. J. Medic., 98, 60-66.

24. Greipp, P. R., Kyle, R. A. Staging, Kinetics and Prognosis in Multiple myeloma. In: Wiernik, P. H., Goldman, J. M., Dutcher, J. P., Kyle, R. A. Neoplastic Diseases of the Blood, Fourth Edition. Cambridge University Press, 2003. p. 488-501.

25. Caligaris-Cappio, F. Biology of the malignant plasma cell. In: Wiernik, P. H., Goldman, J. M., Dutcher, J. P., Kyle, R. A. Neoplastic Diseases of the Blood, Fourth Edition. Cambridge University Press, 2003. p. 58-73. 